\title{
COMPOSITION AND AMOUNT OF MARINE DEBRIS IN THE MANGROVE AREA IN MENGKAPAN VILLAGE, SUNGAI APIT DISTRICT, SIAK REGENCY, RIAU PROVINCE
}

\author{
Silmarita $^{1^{*}}$, Muhammad Fauzi $^{2}$, Eni Sumiarsih ${ }^{2}$ \\ ${ }^{1}$ Student of The Faculty of Fisheries And Marine Science University of Riau, Pekanbaru \\ ${ }^{2}$ Lecturer at the Faculty Of Fisheries And Marine Science University Riau, Pekanbaru \\ *ritasilmarita1951@gmail.com
}

\begin{abstract}
Marine debris is a type of pollutant that commonly found in the mangrove ecosystem. A study aims to investigate the composition, amount and oceanographic parameters that influence the presence of marine debris in Mengkapan mangrove ecotourism area has been conducted from June to August 2018. A survey method was used in this study. Sampling was done three times (once/ two weeks) in 3 observation stations. There were 3 stations namely S1 (settlement area), S2 (ecotourism area) and S3 (port area). Marine debris were collected from 3 plots $(10 \times 10 \mathrm{~m})$ placed along the transect line. Results shown that the types of marine debris found in the observation area were plastic, glass, rubber, fabric, styrofoam, nets, cans, and paper. The most common debris found is plastic $\left(2,603\right.$ items $\left./ \mathrm{m}^{2}\right)$. Total amount of marine debris in the Mengkapan area is 3,232 items $/ \mathrm{m}^{2}\left(18.497 \mathrm{grams} / \mathrm{m}^{2}\right)$. Macrodebris is the most common debris found.
\end{abstract}

Keywords: Plastic remain, glass remain, marine waste, macrodebris

\section{PENDAHULUAN}

Sampah merupakan ancaman polusi yang saat ini menjadi masalah terbesar di dunia. Sampah dapat berasal dari daratan, yang kemudian dibawa oleh aliran air laut dan berakhir di daratan kembali (Opfer et al., 2012). Salah satu jenis sampah yang paling banyak terdapat di wilayah daratan maupun lautan ialah jenis sampah plastik lalu diikuti oleh jenis sampah lainnya. Banyaknya volume sampah yang terdapat di suatu daerah disebabkan oleh kegiatan antropogenik serta aktifitas industri (CBDSTAP, 2012).

NOAA (2013) mendeskripsikan sampah laut (marine debris) sebagai benda padat persistent, diproduksi atau diproses oleh manusia, secara langsung atau tidak langsung, sengaja atau tidak sengaja, dibuang atau ditinggalkan di dalam lingkungan laut. Tipe sampah laut di antaranya plastik, kain, busa, styrofoam,kaca, keramik, logam, kertas, karet dan kayu. Kategori ukuran digunakan untuk mengklasifikasikan marine debris, yaitu megadebris (> $100 \mathrm{~mm}$ ), makrodebris (> 20-100 mm), mesodebris (> 5-20 mm), dan mikrodebris (0.3-5 mm).

Cemaran sampah plastik dapat berdampak pada ekologi laut dan mangrove, karena sampah plastik merupakan faktor utama yang menyebabkan rusaknya vegetasi mangrove, yaitu terjadi gangguan terhadap aerasi udara pada sistem perakaran mangrove. Selain dari dampak ekologi, sampah laut berdampak pada ekonomi masyarakat. Karena dapat mengurangi nilai estetika ekosistem mangrove, sehingga mengakibatkan berkurangnya daya tarik 
para wisatawan untuk berkunjung ke objek wisata mangrove (BPLHD Provinsi DKI Jakarta, 2006 dalam Waryono, 2006).

Pada salah satu kawasan pesisir Kabupaten Siak terdapat kawasan objek wisata mangrove Mengkapan. Selain itu terdapat aktivitas lain yaitu pemukiman, pelabuhan rakyat dan jalur transportasi laut. Aktivitas tersebut memberikan konstribusi pencemaran sampah terutama sampah plastik yang masuk ke kawasan mangrove. Pada kawasan objek wisata mangrove Kampung Mengkapan termasuk wilayah pesisir yang dipengaruhi oleh Sungai Siak dan Selat Malaka. Pengendalian sampah laut (marine debris) akan mempengaruhi kawasan mangrove di Kampung Mengkapan. Smith (2012) menyatakan bahwah sampah laut sebagian akan terbawa di laut dan sebagian besar akan sampai di pantai dan ekosistem mangrove. Sampah laut terdistribusi ke ekosistem mangrove akan terakumulasi di sedimen dan akar mangrove. Pencemaran sampah dapat mempengaruhi kualitas dan fungsi ekosistem mangrove.

Kawasan mangrove Kampung Mengkapan terletak terletak di muara Sungai Siak, potensi marine debris yang terbawa dari hulu Sungai Siak dapat sampai ke muara dan berpotensi masuk ke ekosistem mangrove. Sampah laut yang sudah terdapat di laut dapat pula masuk ke ekosistem mangrove karena proses pasang dan surut. Oleh karena itu potensi sampah laut (marine debris) yang masuk ke ekosistem mangrove Kampung Mengkapan sangat tinggi. Marine debris sangat berbahaya bagi organisme pesisir dan mangrove, maka komposisi dan jenis sampah laut (marine debris) di kawasan ekowisata mangrove Kampung Mengkapan perlu untuk diteliti.

Penelitian ini bertujuan untuk mengetahui komposisi, jenis dan parameter oseanografi yang mempengaruhi sampah laut (marine debris) pada kawasan ekowisata mangrove Kampung Mengakapan Kecamatan Sungai Apit Kabupaten Siak Provinsi Riau.

\section{METOOLOGI PENELITIAN Waktu dan Tempat}

Penelitian ini akan dilaksanakan pada bulan Juni - Juli 2018 di kawasan ekowisata mangrove Kampung Sungai RaMengkapanwa Kecamatan Sungai Apit Kabupaten Siak Provinsi Riau. Identifikasi sampel sampah laut (marine debris) langsung dilakukan di lokasi penelitian (sampel diukur dan timbang bobot sampah berdasarkan pembagian jenis sampel). Sedangkan analisis sampel marine debris dilakukan di Laboratorium Ekologi Manajemen Lingkungan Fakultas Perikanan dan Kelautan Universitas Riau.

\section{Alat dan Bahan}

Tali rapiah, meteran atau rol meter, label dan alat tulis, kamera, Global Positioning System (GPS), sarung tangan, mistar besi, layang layang arus, kompas bidik, stopwatch, timbangan dan kantong plastik.

\section{Metode Penelitian}

Metode yang digunakan dalam penelitian ini adalah metode survey, kemudian pengamatan terhadap marine debris ini dilakukan dengan cara membuat transek garis.

\section{Pengambilan Marine Debris}

Pengambilan marine debris memperhatikan batas jangkauan pangambilan marine debris misalnya daerah jauh jangkauan daerah mangrove ke batas pantai, sehingga pada lokasi penelitian akan dilakukan pengambilan sampah dengan cara penetapan transek garis (line transect) dengan panjang transek $50 \mathrm{~m}$ dengan pembagian 25 meter dari tepi pantai dan 25 meter dari bagian darat wilayah ekosistem mangrove dengan 
ukuran kuadran yaitu 10 x 10 m sedangkan jarak antar stasiun $\pm 100 \mathrm{~m}$.

Pengambilan sampel marine debris dilakukan 3 kali dalam interval waktu 2 minggu sekali dengan membuat 3 titik kuadran di setiap stasiun/transek pada kawasan mangrove. Hal ini dilakukan untuk melihat pengaruh arus surut dan pasang dalam membawa marine debris keluar dari pesisir maupun masuk ke pesisir dan kawasan mangrove Kampung Sungai Rawa.

\section{Tahapan Pengambilan Marine debris}

- Setelah pengumpulan marine debris, maka sampel tersebut di cuci bersih dengan air.

- dikeringkan menggunakan sinar matahari langsung.

- dilakukan pemisahan bedasarkan karakteristik ukuran marine debris yaitu megadebris, makrodebris dan mesodebris (Lippiat et al., 2013).

- Sampel tersebut dimasukkan ke dalam karung diberi label.

- dihitung dan ditimbang dengan menggunakan portable electronic scale (timbangan gantung).

- Setelah itu dilakukan analisis perhitungan jenis (item) dan berat (gram).

\section{Pengukuran dan Analisis Parameter Oseanografi Fisika \\ Pengukuran Arah}

Pengukuran arah dilakukan dengan menggunakan layang-layang arus sebanyak 2 kali pada saat pasang tertinggi dan surut terendah. Layang-layang arus dibiarkan terbawa arus hingga tali lurus, setelah itu mencatat waktu tempuh sepanjang 10 meter dan di bidik dengan menggunakan kompas searah dengan tali untuk menentukan arah arus.

\section{Kecepatan Arus}

Pengambilan kecepatan arus juga dilakukan dengan menggunakan layanglayang arus di masing-masing plot.

$$
\begin{aligned}
& \text { Keterangan : } \\
& \mathrm{V}=\text { Kecepatan arus (m/detik) } \\
& \mathrm{s}=\text { Jarak tempuh layang-layang arus (m) } \\
& \mathrm{t}=\text { Waktu yang digunakan (detik) }
\end{aligned}
$$

\section{Analisis Data}

Data yang diperoleh selama penelitian baik berupa data komposisi dan jenis marine debris serta analisis parameter oseanografi dianalis disajikan dalam bentuk tabel dan grafik.

\section{HASIL DAN PEMBAHASAN}

Jenis-jenis Sampah Laut (marine debris) Jenis-jenis marine debris yang terdapat pada lantai kawasan ekowisata mangrove Kampung Mengkapan selama penelitian terdiri dari plastik, kaca, karet, kain, styrofoam, jaring, kaleng, dan kertas. Jumlah marine debris adalah berkisar 3541.446 item. Berdasarkan jenis marine debris yang ditemukan terdiri dari plastik 2.603 item, kaca 160 item, kertas 152 Item, styrofoam 141 item, kaleng 107 item, Karet 40 item, kain 17 item, jenis marine debris yang paling sedikit ditemukan adalah jaring yaitu 12 item. Marine debris yang didapatkan pada setiap stasiun penelitian berkisar 354-1.446 item (Tabel

\begin{tabular}{|c|c|c|c|c|c|c|}
\hline \multirow{3}{*}{ NO } & \multirow{3}{*}{ Jenis } & \multicolumn{3}{|c|}{ Stasiun } & \multirow{3}{*}{$\begin{array}{c}\text { Total } \\
\text { Debris } \\
\text { Perjenis }\end{array}$} & \multirow{3}{*}{$\%$} \\
\hline & & I & II & III & & \\
\hline & & ....... & Item & $\ldots .$. & & \\
\hline 1 & stik & 1.24 & 182 & 1.175 & 2.603 & 80,54 \\
\hline
\end{tabular}
$1)$.

Tabel 1. Jenis-jenis Marine Debris yang terdapat di Kawasan Ekowisata Mangrove Kampung Mengkapan Saat Penelitian 


\begin{tabular}{|c|c|c|c|c|c|c|}
\hline \multirow[b]{2}{*}{ NO } & \multirow[b]{2}{*}{ Jenis } & \multicolumn{3}{|c|}{ Stasiun } & \multirow{2}{*}{$\begin{array}{c}\text { Total } \\
\text { Debris } \\
\text { Perjenis }\end{array}$} & \multirow[b]{2}{*}{$\%$} \\
\hline & & $\begin{array}{c}\mathbf{I} \\
\ldots \ldots \ldots\end{array}$ & $\begin{array}{c}\text { II } \\
\text { tem .. }\end{array}$ & III & & \\
\hline 2 & Kaca & 11 & 139 & 10 & 160 & 4,95 \\
\hline 3 & Karet & 13 & 3 & 24 & 40 & 1,24 \\
\hline 4 & Kain & 0 & 0 & 17 & 17 & 0,53 \\
\hline 5 & Styrofoam & 75 & 13 & 53 & 141 & 4,36 \\
\hline 6 & Jaring & 2 & 0 & 10 & 12 & 0,37 \\
\hline 7 & Kaleng & 67 & 6 & 34 & 107 & 3,31 \\
\hline 8 & Kertas & 32 & 11 & 109 & 152 & 4,7 \\
\hline & Total & 1.446 & 354 & 1.432 & 3.232 & 100 \\
\hline & $\%$ & 44,74 & 10,95 & 44,31 & 100 & 100 \\
\hline
\end{tabular}

Pada Tabel diatas total jenis marine debris yang ditemukan di Kampung Mengkapan adalah 3.232 item. Jumlah marine debris yang ditemukan di Kampung Mengkapan sangatlah sedikit jika di bandingkan dengan tempat lain. Seperti pada penelitian yang dilakukan oleh Hermawan (2017) di pesisir barat Pulau Selayar Sulawesi Selatan diperkirakan jumlah potongan sampah anorganik sebesar 11.181.000 item. Rendahnya marine debris yang diemukan pada kawasan ekowisata mangrove Kampung Mengkapan dibandingkan Pulau Selayar Sulawesi Selatan diduga karena jumlah rumah tangga yang menghasilkan limbah domestik.

Pada Tabel 1 dapat dilihat bahwa jenis marine debris yang banyak ditemukan pada kawasan ekosistem mangrove Kampung Mengkapan adalah plastik (80,54 \%), dikarenakan sampah plastik selain ringan juga tidak mudah luruh terutama yang digunakan sebagai pembungkus makanan, karena kualitas makanan sangat tergantung pada kemasannnya sehingga produsen meningkatkan kualitas plastik pembungkusnya. Hal ini juga sesuai dengan pernyataan NOAA (2016) yang menjelaskan bahwa sampah plastik merupakan jenis paling umum dan banyak dijumpai serta yang paling berisiko memberikan dampak terhadap organisme laut.

Menurut Hermawan (2017) dampak penumpukan marine debris jenis plastik dapat mengakibatkan tertutupnya substrat dan akar mangrove yang dapat

mengakibatkan tertindihnya anakan mangrove yang akan tumbuh oleh adanya marine debris diatasnya, demikian juga pada biji mangrove yang akan jatuh ke tanah terhalangi oleh marine debris akhirnya kering dan gagal berkecambah.

Marine debris paling banyak didapatkan pada Stasiun 1 yaitu 1.446 item $(44,74 \%)$ (Tabel 1). Tingginya jumlah marine debris disebabkan oleh limbah dari kegiatan domestik, masyarakat sekitar melakukan pembuangan limbah rumah tangga disekitaran hutan mangrove, dan marine debris yang merupakan marine debris yang berasal dari lautan yang dipengaruhi oleh pulau-pulau sekitar dan aliran dari sungai, sehingga menyebabkan merine debris terakumulasi pada mangrove Stasiun I.

Marine debris terendah ditemukan pada Stasiun II 354 item (10,95 \%), diduga di kawasan ekowisata mangrove Kampung Mengkapan. Kegiatan wisata pada kawasan lokasi penelitian Stasiun II tidak memberikan sumbangan terhadap jumlah merine debris di stasiun penelitian ini. Pengunjung atau wisatawan yang 
berkunjung ke kawasan Ekowisata Kampung Mengkapan tersebut tidak menjadi penyumbang sampah secara langsung, melainkan disebabkan oleh pengaruh parameter oseanografi dan kerapatan hutan mangrove di Stasiun II sudah mulai rusak, hingga menyebabkan terjadinya abrasi. Jenis mangrove yang terdapat yaitu Avicennia marina, dan Bruguiera gymnnorhiza.

Penyebaran marine debris dipengengaruhi oleh arus dan arah arus, arah arus pada saat surut menuju ke selatan sedangkan pada saat pasang arus mengarah ke utara (Tabel 3), sehingga menyebabkan terdistibusinya marine debris pada setiap lokasi berbeda. Pernyataan ini sesuai dengan pendapat NOAA (2016) yang mengatakan bahwa sampah laut berasal dari kegiatan di darat dan di laut serta dapat terdistribusi jauh dari sumbernya oleh adanya angin dan arus, arus merupakan salah satu faktor yang mendukung perpindahan sampah laut di perairan yang akhirnya akan terakumulasi di bibir pantai.

\section{Ukuran Sampah Laut (marine debris)}

Pada hasil penelitian ini, karakteristik ukuran marine debris yang ditemukan dibatasi hingga ukuran mega, makro dan meso. Ukuran marine debris yang paling banyak ditemukan di lokasi penelitian ialah jenis ukuran makrodebris pada Stasiun I yaitu 1308, Stasiun III yaitu 1121 item, Stasiun II yaitu 305 item.

Klasifikasi sampah berdasarkan ukuran yang dinyatakan oleh Lippiat et al. (2012), ukuran sampah yang paling banyak ditemukan di lokasi penelitian ialah jenis ukuran makro dengan panjang 2,5 cm - 1 $\mathrm{m}$. Sedangkan yang paling sedikit ditemukan yaitu ukuran megadebris Stasiun III yaitu 3 Item, dan Stasiun I yaitu 1 item yaitu jaring (Tabel 2).

Tabel 2. Klasifikasi Ukuran Sampah Laut (marine debris)

\begin{tabular}{|c|c|c|c|c|c|c|c|c|c|c|}
\hline \multirow{4}{*}{ No } & \multirow{4}{*}{$\begin{array}{c}\text { Jenis } \\
\text { Marine debris }\end{array}$} & \multicolumn{9}{|c|}{ Stasiun } \\
\hline & & \multicolumn{3}{|c|}{ I } & \multicolumn{3}{|c|}{ II } & \multicolumn{3}{|c|}{ III } \\
\hline & & Mega & Makro & Meso & Mega & Makro & Meso & Mega & Makro & Meso \\
\hline & & \multicolumn{9}{|c|}{ 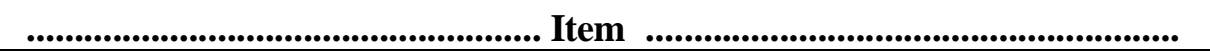 } \\
\hline 1 & Plastik & 0 & 1.152 & 94 & 0 & 167 & 15 & 1 & 1.004 & 169 \\
\hline 2 & Kaca & 0 & 11 & 0 & 0 & 119 & 20 & 0 & 2 & 9 \\
\hline 3 & Karet & 0 & 13 & 0 & 0 & 1 & 0 & 0 & 9 & 16 \\
\hline 4 & Kain & 0 & 0 & 0 & 0 & 0 & 0 & 0 & 10 & 7 \\
\hline 5 & Styrofoam & 0 & 54 & 21 & 0 & 12 & 1 & 0 & 32 & 70 \\
\hline 6 & Jaring & 1 & 1 & 1 & 0 & 0 & 0 & 2 & 8 & 1 \\
\hline 7 & Kaleng & 0 & 67 & 0 & 0 & 6 & 0 & 0 & 34 & 0 \\
\hline \multirow[t]{2}{*}{8} & Kertas & 0 & 10 & 10 & 0 & 0 & 3 & 0 & 22 & 87 \\
\hline & Total & 1 & 1.308 & 126 & $\mathbf{0}$ & 305 & 39 & 3 & 1.121 & 359 \\
\hline \multicolumn{5}{|c|}{$\begin{array}{l}\text { Pada Tabel } 2 \text { ukuran sampah laut marine } \\
\text { debris yang paling dominan sebarannya } \\
\text { yaitu makrodebris terutama jenis plastik. } \\
\text { Sampah plastik selain ringan juga tidak } \\
\text { mudah luruh terutama yang digunakan } \\
\text { sebagai pembungkus makanan, karena }\end{array}$} & \multicolumn{3}{|c|}{$\begin{array}{l}\text { kemasannnya } \\
\text { meningkatkan } \\
\text { pembungkusnya. } \\
\text { macro-debris pa } \\
\text { karena arus pada s } \\
\text { utara menuju } \\
\text { mengindikasikan s }\end{array}$} & $\begin{array}{l}\text { sehings } \\
\text { kuali } \\
\text { Tings } \\
\text { da pe } \\
\text { aat pasa } \\
\text { ampah }\end{array}$ & $\begin{array}{l}\text { ga } \\
\text { tas } \\
\text { ginya } \\
\text { nelitian } \\
\text { ang berge } \\
\text { elatan }\end{array}$ & $\begin{array}{r}\text { orodusen } \\
\text { plastik } \\
\text { sampah } \\
\text { diduga } \\
\text { erak dari } \\
\text { yang }\end{array}$ \\
\hline
\end{tabular}


terbawa dari daerah pemungkiman dan pelabuhan buton. Tingginya sampah macro-debris pada lokasi penelitian sama yang dialami pantai Makassar (Pantai Bob, Pantai Tanjung Bayang, dan Pantai Akarena) yaitu ukuran $>2,5 \mathrm{~cm}-1 \mathrm{~m}$ yang masuk dalam kategori macro-debris (Isman, 2016).

Marine debris yang terdapat pada kawasan mangrove Kampung Mengkapan diduga dipengaruhi oleh faktor oseanografi. Faktor oseanografi yaitu arus dan gelombang membawa merine debris pada saat menjelang pasang sehingga sangat banyak sampah yang terperangkap dan terakumulasi di kawasan mangrove. Hal ini sama juga yang disampaikan NOAA (2016), bahwa arus merupakan salah satu faktor yang mendukung perpindahan sampah laut di perairan dengan jarak yang cukup jauh. Pergerakan arus yang terjadi pada saat pasang memberikan jumlah akumulasi sampah yang sangat berbeda pada lokasi penelitian.

Pada saat air laut pasang atau terjadi badai air laut melampaui pantai yang rendah dan membawa sampah laut ke kawasan mangrove. Pada saat surut sampah laut tersebut tertinggal di kawasan mangrove karena terhalang pantai, sehingga terjadi penumpukan marine debris di daerah mangrove. Tumpukan sampah paling tinggi di daerah yanng menghadap langsung dengan laut, sedangkan kawasan mangrove yang agak ke dalam sedikit berkurang karena terhalangi vegetasi yang rapat. Sampah laut di kawasan tersebut terdiri dari sampah plastik, strerofoam dan lain sebagainya. Marine debris yang tertinggal di permukaan subtrat mangrove akan menutupi bibit mangrove, demikian juga pada biji mangrove yang akan jatuh ke tanah terhalangi oleh marine debris akhirnya kering dan gagal berkecambah.

Bertumpuknya sampah pada vegetasi mangrove akan memberikan dampak seperti membatasi pertumbuhan, juga jelas akan berpengaruh terhadap organisme bentik yang hidup disekitar vegetasi. Mangrove memiliki perenan penting dalam ekosistem pantai, seperti pelindung alamiah garis pantai terhadap erosi. Melihat substrat di lokasi penelitian umumnya berpasir, maka manfaat vegetasi ini sebagai penyangga dalam kawasan pesisir agar tidak terjadi abrasi menjadi sangat berarti.

Menurut Hall et al (2015) sampah plastik (makro) yang hancur menjadi mikroplastik, hal ini dapat menjadi salah satu sumber makanan dan masuk kedalam jaringan mesentrial terumbu karang. Mikroplastik yang berasal dari makroplastik menjadi bahan yang beracun apabila masuk kedalam tubuh biota laut (Andrady, 2011) dan mengganggu kesehatan (Cole et al., 2011) seperti hati di ikan (Rochman et al., 2013). Potongan plastik dapat berpindah dari Konsumen I ke Konsumen ke II (Wright et al., 2013) dan ke manusia melalui proses rantai makanan (Farrell \& Nelson, 2013). Apabila bahan plastik masuk kedalam tubuh manusia melalui proses rantai makanan dengan makan ikan, maka akan terganggu kesehatan terutama pada ibu hamil dan anak-anak (Halden, 2010).

\section{Parameter Lingkungan}

Parameter lingkungan yang digunakan dalam penelitian ini adalah parameter oseanografi dari kecepatan arus dan arah arus. Mason (1981) mengelompokkan kecepatan arus menjadi 5 bagian, diantaranya ; Arus sangat cepat (>1 m/s), cepat $(0,5-1 \mathrm{~m} / \mathrm{s})$, sedang $(0,25$ $-0,5 \mathrm{~m} / \mathrm{s})$, lambat $(0,01-0,25 \mathrm{~m} / \mathrm{s})$, dan sangat lambat $(<0,01 \mathrm{~m} / \mathrm{s})$. Pantai Mengkapan merupakan lokasi yang memiliki kategori arus sedang dengan ratarata $0,27 \mathrm{~m} /$ detik pada saat menuju surut, $0,19 \mathrm{~m} /$ detik saat surut, $0,26 \mathrm{~m} /$ detik pada 
saat menuju pasang dan $0,35 \mathrm{~m} /$ detik pada

saat pasang (Tabel 3).

Tabel 3. Kecepatan Arus dan Arah Arah Arus

\begin{tabular}{clccc}
\hline No & \multicolumn{1}{c}{ Keadaan } & Waktu & Arah & Arus (m/s) \\
\hline 1 & Menuju Pasang & 11.30 & Utara & 0,26 \\
2 & Pasang & 13.30 & Selatan & 0,35 \\
3 & Menuju Surut & 08.00 & Selatan & 0,27 \\
4 & Surut & 09.30 & Utara & 0,19 \\
\hline \multicolumn{2}{r}{ hingga } & terjadi penumpukan & pada suatu \\
& Pada Tabel 3 dapat dilihat bahwah & tempat.
\end{tabular}

arah arus pada saat menuju surut ke barat laut sedangkan pada saat surut arus mengarah ke utara dan kembali mengarah ke selatan pada saat menuju pasang. Hal ini bisa saja terjadi dikarenakan arah arus yang sejajar dengan garis pantai ditambah terdapat pulau di depan pantai yang menyebabkan kecepatan arus meninggkat karena proses penyempitan. Selanjutnya, perbedaan letak geografis serta keberadaan ekosistem seperti mangrove pada ketiga pulau ini, cenderung memberikan pengaruh terhadap hasil parameter oseanografi yang dilakukan.

Marine debris dapat berpindah dengan konstibusi dari faktor oseanografi hingga terjadi penumpukan pada suatu tempat. Kondisi arah arus yang sejajar dengan garis pantai sangat memungkinkan dalam proses penyebaran sampah laut. Pada saat pasang hingga menuju surut, sampah dipredikasi berasal dari barat daya dan menyumbang banyak sampah yang pada dasarnya pelabuhan Buton berada pada bagian Selatan dan paling dekat dengan perairan selat panjang dan selat malaka. Sedangkan pada saat kondisi kondisi surut dan menuju pasang sampah akan kembali terangkut dan terbawah kembali menuju Utara. Dapat diasumsikan bahwa sampah laut dapat berpindah dengan konstibusi dari faktor oseanografi

\section{KESIMPULAN DAN SARAN Kesimpulan}

Sampah laut (marine debris) di ekowisata mangrove Kampung Mengkapan terdiri dari sampah plastik, kaca, karet, kain, styrofoam, jaring, kaleng, dan kertas. Total

jumlah (item) sampah laut (marine debris) yang didapatkan yaitu 3.232 item dan total berat $18.497 \mathrm{~g}$, jenis sampah yang paling dominan di setiap lokasi adalah sampah plastik 2.603 item.

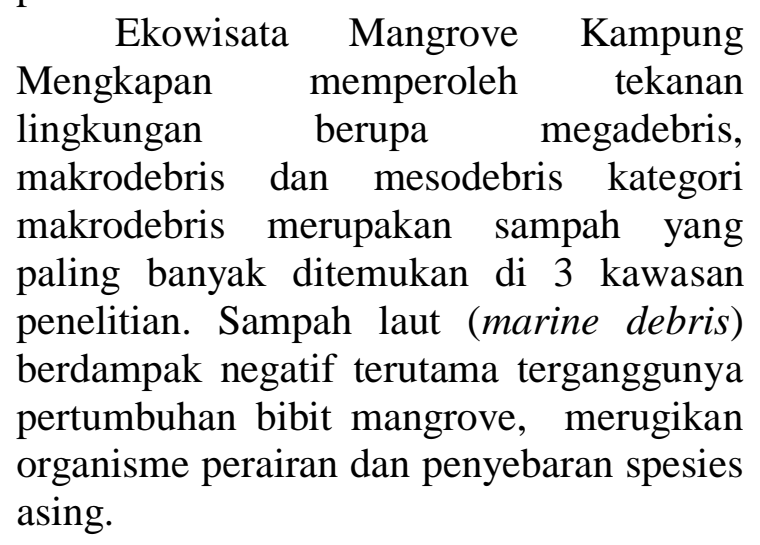

\section{Saran}

Perlunya peran pemerintahan terhadap masyarakat akan peningkatan kesadaran, pengetahuan dan keterampilan dalam mengelolah marine debris.

\section{DAFTAR PUSTAKA}

1. Andrady, A.L., 2011. Microplastics in the Marine Environment. Marine pollution bulletin. 62(1), 1596-1605. 
2. CBD. Convention on Biological Diversity. 2012. Impacts of Marine Debris On Biodiversity. Currents Status and Potential Pollution. CBD Technical Series No.67.

3. Cole, M., P. Lindeque, C. Halsband and Galloway, T.S., 2011. Microplastics as Contaminantsin the Marine Environment: A review. Mar.Pollut. Bull. 62(1), 25882597.

4. Farrell, P. \& Nelson, K., 2013. Trophic Level Transfer of Microplastic: Mytilus edulis (L.) to Carcinus maenas (L.). Environ. Pollut. 177(1), 1- 3.

5. Gall SC, Thompson RC. 2015. The impact of debris on marine life. Marine Pollution Bulletin. 92(1-2), 170-179.

6. Halden, R.U., 2010. Plastics and Health Risks. Annu. Rev. Publi. Heal. 31(5), 179-194.

7. Hall, N.M., K.L.E. Berry, L. Rintoul \& M.O., Hoogenboom. 2015. Microplastic Ingestion by Scleractinian Corals. Mar. Biol. 162(4), 725-732.

8. Hermawan. 2017.Analisis Jenis Dan Bobot Sampah Laut Di Pesisir Barat Pulau Selayar Sulawesi Selatan. Bogor : Institut Pertanian Bogor

9. Isman. F.M,. 2016. Identifikasi Sampah Laut di Kawasa Wisata Pantai Kota Makassar. Skripsi. Fakultas Ilmu Kelautan dan Perikanan. Unhas. Makassar.

10. Kemenperin [Kementerian Perindustrian dan Perdagangan]. 2013.Konsumsi plastik 1,9 juta ton [Internet]. [diunduh 2013 Des 7].Tersedia pada: http: //www.kemenperin.go.id/artikel/6262/Semester-I,-Konsumsi-Plastik-1,9- Juta-Ton.

11. Lippiat, S. S. Opfer, and C, Arthur. 2012. Marine Debris and Monitoring Assesment. NOAA.

12. , S., S Opfer, and C Arthur,. 2013. Marine Debris and Monitoring Assesment.

13. Mason, C. F. 1981. Biology of Freshwater Pollution Longman. New York.

14. [NOAA] National Oceanic and Atmospheric Administration. 2013. Programmatic Environmental Assessment (PEA) for the NOAA Marine Debris Program (MDP). Maryland (US): NOAA. $168 \mathrm{p}$.

15. 2016. Marine Debris Impacts on Coastal and Benthic Habitats. NOAA Marine Debris Habitat Report.

16. Opfer, S., C Arthur., and S Lippiat. 2012. Marine Debris Shoreline Survey Field Guide. NOAA

17. Rochman, M., C., A. Tahir, L Susan., Williams., V Dolores., Baxa., L Rosalyn., T., M Jeffrey. T, Foo-Ching., S.Werorilangi and J Swee. Teh. 2015. Anthropogenic Debris in Seafood: Plastic Debris and Fibers From Textiles in Fish and Bivalves Sold For Human Consumption. Journal. Nature.

18. Smith SDA. 2012. Marine debris: A proximate threat to marinesustainability in Bootless Bay, Papua New Guinea. Mar Pollut Bull64: 1880- 1883.doi: 10.1016/j.marpolbul.2012.06.01.

19. STAP [Scientific and Technical Advisory Panel]. 2011. Marine Debris asa Global Environmental Problem: Introducing a Solutions BasedFramework Focused on Plastic. A STAP Information Document. Global Environment Facility. Washington DC (US).

20. Wright, S. L., R. C., Thompson, \& T. S., Galloway. 2013. The physical impacts of microplastics on marine organisms: a review. Environmental Pollution, 178(5), 483492. 